\title{
Ex-vivo Evaluation of the Intrapulpal Temperature Variation and Fracture Strength in Teeth Subjected to Different External Bleaching Protocols
}

\author{
Renata Araújo COELHO \\ Alcides Gomes OLIVEIRA \\ Aline Evangelista SOUZA-GABRIEL \\ Silvio Rocha C. SILVA \\ Yara T. Correa SILVA-SOUSA \\ Ricardo Gariba SILVA \\ University of Ribeirão Preto, Dental School, Ribeirão Preto, SP, Brazil
}

\begin{abstract}
This study evaluated the influence of bleaching protocols on intrapulpal temperature and fracture strength of the bleached teeth. Ninety maxillary incisors were assigned to 9 groups $(\mathrm{n}=10)$ : $\mathrm{G} 1: 35 \%$ carbamide peroxide $(35 \% \mathrm{CP}), \mathrm{G} 2: 38 \%$ hydrogen peroxide (38\% $\mathrm{HP})$, G3: halogen light, G4: LED-laser, G5: 35\% CP + halogen light, G6: 38\% HP + halogen light, G7: 35\% CP + LED-laser, G8: 38\% HP + LED-laser, and G9: no treatment (control). Pulp space was widened, a thermocouple was introduced through the apex up to the pulp chamber and the temperature was recorded $\left({ }^{\circ} \mathrm{C}\right)$. The fracture strength $(\mathrm{kN})$ was determined using an Instron machine. Data were analyzed by ANOVA and Tukey's test $(\mathrm{p}<0.05)$. The halogen light alone $(1.10 \pm 0.24)(\mathrm{G} 3)$ and associated with $38 \%$ HP $(1.15$ $\pm 0.30)(\mathrm{G} 6)$ produced the highest temperature increase, statistically different $(\mathrm{p}<0.05)$ from the other groups. $\mathrm{G} 1(0.15 \pm 0.06)$ and G6 $(0.19 \pm 0.07)$ produced the lowest values, statistically different $(\mathrm{p}<0.05)$ from G5 $(0.65 \pm 0.49)$. The bleaching protocols increased the temperature, but no increment exceeded the critical value of $5.6^{\circ} \mathrm{C}$. Neither $35 \% \mathrm{CP}$ nor $38 \% \mathrm{HP}$ or the light sources alone altered the fracture strength of the teeth.
\end{abstract}

Key Words: fracture resistance, temperature, bleaching, hydrogen peroxide, LED system.

\section{INTRODUCTION}

Tooth bleaching is a procedure in which chemical products catalyzed or not by heat or light sources promote chromatic alterations in the dental tissues. Bleaching is achieved from an oxi-reduction reaction in which reactive oxygen species and some free radicals released from the degradation of the bleaching agent attack the longchained, dark-colored chromophore molecules present in the dental tissues and split them into smaller, less colored and more diffusible molecules, producing the whitening effect (1). Due to its reactive properties, hydrogen peroxide (HP) is the main active chemical component of most agents used in tooth bleaching therapies. HP can be used in its pure form or as the final product of the degradation of other bleaching substances, such as sodium perborate and carbamide peroxide (CP) (2).

Light sources, such as blue halogen light, light- emitting diode (LED)-laser system, blue plasma arc lamp, argon laser, GaAlAs diode laser, ultraviolet light, Er:YAG laser and $\mathrm{CO}_{2}$ laser, are used to catalyze the bleaching process by intensifying the oxi-reduction reaction and accelerating the release of hydroxyl $\left(\mathrm{OH}^{-}\right)$ radicals (3-5). The catalyst effect of photoactivation permits the application of the bleaching gel several times in the same bleaching session (4).

Although vital tooth bleaching associated with photoactivation has become very popular in the last decade, some adverse effects might occur. In order to bleach the teeth, HP must penetrate through the enamel to reach the underlying dentin, which is mostly responsible for tooth color (1). The penetration of HP is influenced by a number of factors including the exposure time, osmotic pressure and concentration of the bleaching gel as well as the number of bleaching sessions $(1,2)$.

In addition, light sources used to catalyze the 
action of the bleaching agent produce a temperature rise in the pulp chamber that may cause irreversible thermal pulpal damage, including pulp necrosis, if it exceeds the threshold of temperature rise for pulp damage (3). According to Zach and Cohen (6) temperature increments above the critical value of $5.6^{\circ} \mathrm{C}$ are potentially threatening to pulp.

It has been demonstrated that the microhardness and modulus of elasticity of enamel and dentin are altered by HP-containing bleaching agents (7). These events may be attributed to the decrease of enamel inorganic content and dentin organic content as well as morphological alterations in the dental substrate (8), which may affect the fracture strength of bleached teeth.

Cavalli et al. (9) evaluated the effect of $\mathrm{CP}$ on enamel and found lower bond strength after an $8 \mathrm{~h} /$ day treatment during 14 days. In another study (10), the direct application of $10 \% \mathrm{CP}$ and $3 \%$ and $30 \% \mathrm{HP}$ on dentin during 8 weeks has been shown to cause a significant decrease of the fracture strength of human teeth. The indirect application of these bleaching agents to dentin through the overlying enamel did not cause a significant decrease of the fracture strength.

The purpose of this ex vivo study was to evaluate the intrapulpal temperature variation and the fracture strength of sound teeth subjected to external bleaching with $38 \% \mathrm{HP}$ and $35 \% \mathrm{CP}$ photoactivated or not with halogen light and a LED-laser system.

\section{MATERIAL AND METHODS}

The research protocol was reviewed and approved by the Research Ethics Committee of the University of Ribeirão Preto, Brazil. Ninety extracted human maxillary incisors with complete root formation, single canal, no internal resorptions or calcifications, and no accentuated root curvatures were selected. The apical 2 $\mathrm{mm}$ were resected with a carborundum disk and a \#10 K-file(Dentsply/Maillefer, Ballaigues, Switzerland) was introduced through the apical opening until reaching the roof of the pulp chamber to create space for the further placement of a thermocouple. The canals were widened with \#3-6 Largo burs (Dentsply/Maillefer) with irrigation with $2 \mathrm{~mL}$ of $1 \% \mathrm{NaOCl}$ before and between the use of the burs and at each change of instrument.

After canal preparation, a high-precision K-type thermocouple (chromel-alumel) was introduced through the apical opening up to the pulp chamber and was withdrawn $1 \mathrm{~mm}$ short of the length measured with the K-file in order to be positioned in the most central portion of the pulp chamber, which was confirmed radiographically. The thermocouple was connected to a digital thermometer (MT-600; MINIPA, São Paulo, SP, Brazil). Orthodontic wires (1 mm diameter x $5 \mathrm{~mm}$ long) were fixed to the cementoenamel junction and incisal edge of the buccal surface of each tooth with a quick-setting cyanoacrylate ester adhesive (Super Bonder ${ }^{\circledR}$; Loctide, Piracicaba, SP, Brazil) to standardize the volume of bleaching gel applied, avoiding flowing off the tooth surface. The tooth/thermocouple sets were placed in an adjustable acrylic device, which kept them in a standardized vertical position during the experimental procedures.

Nine groups of 10 specimens each were formed from the interactions between bleaching agents $\mathrm{x}$ light sources. In G1, a 38\% HP gel (Ultradent Products Inc., South Jordan, UT, USA) was applied to the buccal surface of the teeth for $20 \mathrm{~s}$. The red activator was mixed with the colorless bleaching gel at the moment of use, according to the manufacturer's instructions. In G2, a $35 \%$ CP gel (Ultradent Products Inc.) was applied to the buccal surface of the teeth for the same time. This product has no colorant. Specimens in groups G3 to G8 were irradiated with light sources fixed to the adjustable acrylic device by metallic grips in a perpendicular position to the buccal surface of the teeth at $10-\mathrm{mm}$ distance. In $\mathrm{G} 3$ and $\mathrm{G} 4$, no bleaching treatment was done and the buccal surface of the teeth was irradiated for $20 \mathrm{~s}$ with a halogen curing unit (Dabi Atlante, Ribeirão Preto, SP, Brazil) and a LED-laser system (Brightness, Kondortech, São Carlos, SP, Brazil), respectively. In G5 and G6, 35\% CP and 38\% HP, respectively, were photoactivated with the halogen light for $20 \mathrm{~s}$, while in G7 and G8 the bleaching gels were catalyzed with a LED-laser system for the same time. In G9 (control), no bleaching gel or light source was used.

The experiment was conducted at thermostatically regulated room temperature around $23^{\circ} \mathrm{C}$. After each intrapulpal temperature reading, the temperature of the whole system was allowed to stabilize and return to the original values and a new reading was done thereafter. After each intrapulpal temperature reading, the bleaching agent was aspirated and any gel traces on tooth surface were removed with cotton pellets. All bleaching treatments were repeated 6 consecutive times with 20 -s intervals between the applications within the same session. The variation of temperature in the pulp chamber was calculated as being the difference between 
the initial temperature (IT) and highest temperature (HT) recorded during the bleaching protocol $\left({ }^{\circ} \mathrm{C}\right)$.

Next, in preparation for the fracture strength test, the teeth were vertically fixed with wax in the center of rectangular metallic matrices $(16.5 \mathrm{~mm}$ high $\mathrm{x} 31.0$ $\mathrm{mm}$ long) that filled with colorless autopolymerizing acrylic resin (Jet Clássico, São Paulo, SP, Brazil) up to the cementoenamel junction of the roots. The fracture strength test was performed immediately after application of the bleaching agents and light sources alone and after photoactivation of the bleaching gels.

In order to maintain the specimens at $45^{\circ}$ angle to the horizontal plane during the test, a stainless steel base $(3 \times 3 \times 8.5 \mathrm{~cm})$ was designed. The roots embedded in the cylinders had the same inclination. This set was positioned in an Instron 4444 universal testing machine (Instron Corporation, Canton, MA, USA). The force was applied by a stainless steel ball-ended rectangular tip at the interface between the incisal and middle thirds of the palatal surface at $135^{\circ}$ angle with the long tooth axis. The tip base was coupled to a load cell running at a crosshead speed of $1 \mathrm{~mm} / \mathrm{min}$ until fracture occurred.

\section{RESULTS}

\section{Analysis of Temperature}

Results of intrapulpal temperature variation $\left({ }^{\circ} \mathrm{C}\right)$ are presented in Table 1 . There were statistically significant differences $(p<0.05)$ among the groups regarding the intrapulpal temperature variation. The

Table 1. Mean $( \pm \mathrm{SD})$ intrapulpal temperature variation $\left({ }^{\circ} \mathrm{C}\right)$ in each group.

\begin{tabular}{lc}
\hline Experimental groups & Mean $\pm \mathrm{SD}$ \\
\hline $38 \% \mathrm{H}_{2} \mathrm{O}_{2}+$ halogen light (G6) & $1.15 \pm 0.30 \bullet$ \\
Halogen light (G3) & $1.10 \pm 0.24$ \\
$35 \% \mathrm{CP}+$ halogen light (G5) & $0.68 \pm 0.25 \boldsymbol{\Delta}$ \\
LED-laser (G4) & $0.49 \pm 0.10 \bullet \boldsymbol{\Delta}$ \\
$35 \% \mathrm{CP}+\mathrm{LED}-$ laser (G7) & $0.37 \pm 0.08 \bullet \bullet$ \\
$38 \% \mathrm{H}_{2} \mathrm{O}_{2}+\mathrm{LED}-\operatorname{laser}(\mathrm{G} 8)$ & $0.36 \pm 0.07 \bullet \bullet$ \\
$38 \% \mathrm{H}_{2} \mathrm{O}_{2}(\mathrm{G} 2)$ & $0.19 \pm 0.10 \bullet$ \\
$35 \% \mathrm{CP}(\mathrm{G} 1)$ & $0.13 \pm 0.07 \bullet$ \\
\hline
\end{tabular}

$\mathrm{CP}=$ carbamide peroxide. $\mathrm{H}_{2} \mathrm{O}_{2}=$ hydrogen peroxide. Different symbols indicate statistically significant difference $(p<0.05)$. halogen light alone $(1.10 \pm 0.24)(\mathrm{G} 3)$ and associated with $38 \%$ HP $(1.15 \pm 0.30)(\mathrm{G} 6)$ had the highest temperature increases, being similar to each other $(p>0.05)$ and significantly different $(\mathrm{p}<0.05)$ from the other groups. G4 (LED-laser; $\left.0.49 \pm 0.10^{\circ} \mathrm{C}\right)$ and $\mathrm{G} 5(35 \% \mathrm{CP}$ plus halogen light; $0.68 \pm 0.25^{\circ} \mathrm{C}$ ) had the lowest increments of temperature, being similar to each other $(p>0.05)$ and significantly different $(\mathrm{p}<0.05)$ from the other groups.

When the light sources were used alone, halogen light promoted significantly greater temperature rise $(1.10$ $\left.\pm 0.24^{\circ} \mathrm{C}\right)$ than the LED-laser $\left(0.49 \pm 0.10^{\circ} \mathrm{C}\right)(\mathrm{p}<0.05)$. The LED-laser system alone had an intermediate behavior sometimes similar to the association between $35 \% \mathrm{CP}$ and halogen light, sometimes similar to its associations with the two bleaching agents evaluated.

The groups in which the bleaching agents were used alone or in association with the LED-laser produced the lowest intrapulpal temperature increments, without significant difference $(p>0.05)$ from each other.

\section{Analysis of Fracture Strength}

Fracture strength results are presented in Table 2 $(\mathrm{kN})$. There were significant differences $(\mathrm{p}<0.05)$ among the groups regarding the fracture strength.

G5 (35\% CP plus halogen light) presented the highest mean fracture strength value $(0.65 \pm 0.49)$, differing significantly $(\mathrm{p}<0.05)$ from G1 $(35 \% \mathrm{CP}$; $0.15 \pm 0.06)$ and G6 (38\% HP plus halogen light; 0.19 $\pm 0.07)$, which had the lowest mean fracture strength

Table 2. Mean $( \pm \mathrm{SD})$ force $(\mathrm{kN})$ needed for fracturing the teeth in each group.

\begin{tabular}{lc}
\hline Experimental groups & Mean $\pm \mathrm{SD}$ \\
\hline $35 \% \mathrm{CP}+$ halogen light (G5) & $0.65 \pm 0.49 \boldsymbol{\Delta}$ \\
Control (G9) & $0.62 \pm 0.47 \boldsymbol{\Delta} \bullet$ \\
$38 \% \mathrm{H}_{2} \mathrm{O}_{2}(\mathrm{G} 2)$ & $0.59 \pm 0.37 \boldsymbol{\Delta} \bullet$ \\
Halogen light (G3) & $0.42 \pm 0.22 \boldsymbol{\bullet}$ \\
LED-laser (G4) & $0.37 \pm 0.15 \boldsymbol{\Delta}$ \\
$35 \% \mathrm{CP}+\mathrm{LED}-$ laser $(\mathrm{G} 7)$ & $0.36 \pm 0.30 \boldsymbol{\bullet}$ \\
$38 \% \mathrm{H}_{2} \mathrm{O}_{2}+\mathrm{LED}-\mathrm{laser}(\mathrm{G} 8)$ & $0.34 \pm 0.21 \boldsymbol{\bullet}$ \\
$38 \% \mathrm{H}_{2} \mathrm{O}_{2}+$ halogen light $(\mathrm{G} 6)$ & $0.19 \pm 0.07 \bullet \bullet$ \\
$35 \% \mathrm{CP}(\mathrm{G} 1)$ & $0.15 \pm 0.06 \bullet \bullet$ \\
\hline
\end{tabular}

$\mathrm{CP}=$ carbamide peroxide. $\mathrm{H}_{2} \mathrm{O}_{2}=$ hydrogen peroxide. Different symbols indicate statistically significant difference $(\mathrm{p}<0.05)$. 
values. The control group $(0.62 \pm 0.47), 38 \% \mathrm{HP}(\mathrm{G} 2$; $0.34 \pm 0.21$ ), halogen light (G3;0.42 \pm 0.22$)$, and the LED-laser system alone $(0.37 \pm 0.15)$ and associated with $35 \% \mathrm{CP}(0.36 \pm 0.30)$ and $38 \% \mathrm{HP}(0.34 \pm 0.21)$ had intermediate fracture strength values, sometimes similar to the group with the highest value, sometimes similar to the groups with the lowest values.

Fracture strength of the teeth subjected to the bleaching agents and/or light sources did not differ significantly $(\mathrm{p}>0.05)$ from that of the control group.

\section{DISCUSSION}

The temperature variations recorded in the present study were always positive, which means that the temperature measured after application of the bleaching agent, light source or both was always higher than the initial temperature. Maximum increments of $1.15^{\circ} \mathrm{C}$ on average were observed, which is in contrast with the results of Eldeniz et al. (11). However, those authors filled the pulp chamber with heat-conducting substance, which allowed a more accurate capture of thermal energy by the thermocouple compared to the present study, in which the pulp chamber received only the thermocouple. In addition, the light source was used for $40 \mathrm{~s}$, which is a two-fold longer activation time than that used in the present study.

Regarding the use of the light sources, different authors $(5,12)$ have found similar results to those of the present study, in which the halogen light cause greater temperature rise than the LED-laser system. It is speculated that since the halogen light is generate by an incandescent filament, it transmits more heat than the LED-laser, which is a cold light originated from semiconductors (4). In addition, vital tooth bleaching catalyzed by diode laser has been shown to cause less dentin and gingival sensitivity (13).

The bleaching agents when used alone produced small increments of temperature, which may be explained by the exothermic chemical reaction that breaks the HP down (14). In contact with the dental tissues, the CP dissociates in urea and HP. Urea is decomposed in carbon dioxide and ammonia, and HP is decomposed in water and nascent oxygen, with release of energy $(1,15)$. The reactive and instable oxygen molecules attack the longchained, dark-colored chromophore molecules split them into smaller, less colored molecules (15).

In the present study, the association of the peroxide-based bleaching agents with halogen light did not produce a greater temperature rise than the sum of the alone. The halogen light did not intensify the oxi-reduction chemical reaction of $38 \% \mathrm{HP}$ and $35 \% \mathrm{CP}$, and caused greater release of thermal energy; it only accelerated the oxi-reduction reaction. The association of $35 \% \mathrm{CP}$ and halogen light produced a significant decrease in the intrapulpal temperature. This was probably due to the fact that the bleaching gel is transparent and reflects part of the light delivered on it, unlike the $38 \%$ HP gel that has a red colorant in its composition and absorbs the light more effectively (4). However, it should be mentioned that the aforementioned observations refer only to light absorption, which may implicate less temperature diffusion to the adjacent regions such as dental surface. There was no concern about the intensity and length of tooth bleaching because this was not the goal of the study, though it has been demonstrated that this association does not increase the bleaching efficacy $(13,16)$.

All experimental conditions evaluated in this study produced temperature variations below the critical value of $5.6^{\circ} \mathrm{C}(6)$. This result can be attributed to the fact that the temperature readings in that study were made directly on the thermocouple without using natural teeth, as in the present study, and confirms that dentin is a natural thermal insulating and reduces significantly the amount of heat that reaches the pulp chamber (3).

Regarding the fracture strength, G5 (35\% CP + halogen light) presented the highest mean values, while $35 \% \mathrm{CP}$ alone and the association of $38 \% \mathrm{HP}$ and halogen light presented lowest mean values. However, none of these groups differed significantly from the control group, which suggests that neither the bleaching agents, nor the light sources or the associations of both affected the fracture strength of the teeth (2).

The highest temperature increments occurred when the halogen light was associated with $38 \%$ HP (G6) or used alone (G3), which discards the hypothesis of a correlation between temperature rise and fracture strength decrease in teeth undergoing external tooth bleaching. The analysis should thus be limited to the chemical effects of the bleaching substances (HP and $\mathrm{CP})$ on the dental tissues $(1,15)$.

The literature has demonstrated that the application of HP on enamel and dentin decreases microhardness and module of elasticity (7). HP also produces morphological alterations in dental surface, affects intertubular and peritubular dentin (8) and causes structural alterations to the hydroxyapatite due to the 
ionic bonds that weaken its structure (17). However, the findings of the present study showed that the evaluated protocols did not affect the fracture strength of the teeth. These results corroborate those of a previous study (18) that evaluated the flexural strength and modulus of elasticity of bovine teeth bleached with $10 \% \mathrm{CP}$ during $6 \mathrm{~h}$ /day within a 14-day period. Conversely, Khoroushi et al. (19) verified that the fracture resistance of endodontically treated teeth decreases after bleaching with different HP bleaching protocols. The structural alterations resulting from the action of the bleaching agents may be reversed by remineralization with fluoride substances (20) or using sodium ascorbate (19).

In this study, the halogen light alone or associated with $38 \%$ HP produced the greatest increments in intrapulpal temperature, though without exceeding the critical $5.6^{\circ} \mathrm{C}$ value for pulpal damage. Neither the $35 \%$ $\mathrm{CP}$ and $38 \% \mathrm{HP}$ alone or photoactivated, nor the light sources alone altered the fracture strength of the teeth subjected to external bleaching.

It should be highlighted that the exact mechanism by which the bleaching agents act on dentin is not yet clearly understood (15). It has been speculated that the adverse effects of these substances on dental tissues are related to their $\mathrm{pH}$ rather than to the chemical agents themselves (1). Further research is needed to elucidate the mechanisms of action of the bleaching agents on the dental tissues, their diffusion through enamel and dentin, the byproducts resulting from their degradation and their effects, as well as the role of the light sources.

\section{RESUMO}

Este estudo avaliou a influência de protocolos de clareamento na temperatura intrapulpar e resistência à fratura de dentes clareados. Noventa incisivos superiores foram divididos em 9 grupos $(n=10)$ : G1: peróxido de carbamida a 35\% (PC 35\%), G2: peróxido de hidrogênio a 38\% (PH 38\%), G3: luz halógena, G4: LED-laser, G5: PC 35\% + luz halógena, G6: PH 38\% + luz halógena, G7: PC 35\% + LED-laser, G8: PH 38\% + LED-laser e G9: sem tratamento (controle). O canal radicular foi alargado, um termopar foi introduzido no ápice até a câmara pulpar e a temperatura foi calculada $\left({ }^{\circ} \mathrm{C}\right)$. A resistência à fratura $(\mathrm{kN})$ foi determinada em máquina Instron. Os dados foram analisados por análise de variância e teste de Tukey $(\mathrm{p}>0,05)$. A luz halógena utilizada isoladamente $(1,10 \pm 0,24)(\mathrm{G} 3)$ e associada ao PH $38 \%(1,15 \pm$ $0,30)(\mathrm{G} 6)$ proporcionaram os maiores valores de temperatura, sendo estatisticamente diferentes dos demais grupos $(\mathrm{p}<0,05)$. O G1 $(0,15 \pm 0,06)$ e o $G 6(0,19 \pm 0,07)$ produziram os menores valores de resistência à fratura, sendo estatisticamente diferentes $(\mathrm{p}<0,05)$ do G5 $(0,65 \pm 0,49)$. Os protocolos de clareamento aumentaram a temperatura, mas nenhum incremento excedeu o valor crítico de $5,6^{\circ} \mathrm{C}$. O PC $35 \%$, PH $38 \%$ e as fontes de luz utilizadas isoladamente não alteraram a resistência à fratura dos dentes.

\section{REFERENCES}

1. Plotino G, Buono L, Grande NM, Pameijer CH, Somma F. Nonvital tooth bleaching: a review of the literature and clinical procedures. $\mathrm{J}$ Endod 2008;34:394-407.

2. Pobbe PO, Viapiana R, Souza-Gabriel AE, Marchesan MA, SousaNeto MD, Silva-Sousa YT, et al.. Coronal resistance to fracture of endodontically treated teeth submitted to light-activated bleaching. J Dent 2008;36:935-939.

3. Sydney GB, Barletta FB, Sydney RB. In vitro analysis of effects of heat used in dental bleaching on human dental enamel. Braz Dent J 2002;13:166-169.

4. Wetter NU, Barroso MCS, Pelino JEP. Dental bleaching efficacy with diode laser and LED irradiation: an in vitro study. J Clin Laser Med Surg 2004;35:254-258.

5. Zhang C, Wang X, Kinoshita JI, Zhao B, Toko T, Kimura Y, et al.. Effect of KTP laser irradiation, diode laser, and LED on tooth bleaching: a comparative study. Photomed Laser Surg 2007;25:91-95.

6. Zach L, Cohen G. Pulp response to externally applied heat. Oral Surg Oral Med Oral Pathol 1965;19:515-530.

7. Chng HK, Yap AUJ, Wattanapayungkul P, Sim CPC. Effect of traditional and alternative intracoronal bleaching agents on microhardness of human dentine. J Oral Rehabil 2004;31:811-816.

8. Kawamoto K, Tsujimoto Y. Effects of the hydroxyl radical and hydrogen peroxide on tooth bleaching. J Endod 2004;30:45-50.

9. Cavalli V, Giannini M, Carvalho RM. Effect of carbamide peroxide bleaching agents on tensile strength of human enamel. Dent Mater 2004;20:733-739.

10. Tam IE, Kuo VY, Noroozi A. Effect of prolonged direct and indirect peroxide bleaching on fracture toughness of human dentin. J Esthet Restor Dent 2007;19:100-109.

11. Eldeniz AU, Usumez A, Usumez S, Ozturk N. Pulpal temperature rise during light-activated bleaching. J Biomed Mater Res B Appl Biomater 2005;72:254-259.

12. Usumez A, Ozturk N. Temperature rise during resin cement polymerization under a ceramic restoration: Effect of type of curing units. Int J Prosthodont 2004;17:200-204.

13. Gurgan S, Cakir FY, Yazici E. Different light-activated in-office bleaching systems: a clinical evaluation. Lasers Med Sci 2010;25:817822 .

14. Benon HJB, Arudi RI, Sutherland MW. A study of the reactivity of H02/02- with unsaturated fatty acids. J Biol Chem 1983;25:4759-4761.

15. Tredwin CJ, Naik S, Lewis NJ, Scully C. Hydrogen peroxide toothwhitening (bleaching) products: review of adverse effects and safety issues. Br Dent J 2006;200:371-376.

16. Ontiveros JC, Paravina RD. Color change of vital teeth exposed to bleaching performed with and without supplementary light. J Dent 2009;37:840-847.

17. Attin T, Muller T, Patyk A, Lennon AM. Influence of different bleaching systems on fracture toughness and hardness of enamel. Oper Dent 2004;29:188-195.

18. Tam LE, Lim M, Khanna S. Effect of direct peroxide bleach application to bovine dentin on flexural strength and modulus in vitro. J Dent 2005;33:451-458.

19. Khoroushi M, Feiz A, Khodamoradi R. Fracture resistance of endodontically-treated teeth: effect of combination bleaching and an antioxidant. Oper Dent 2010;35:530-537.

20. Bistey T, Nagy IP, Simó A, Hegedus C. In vitro FT-IR study of hydrogen peroxide on superficial tooth enamel. J Dent 2007;35:325-330.

Accepted October 21, 2010 